\title{
Investigation of the Aerodynamic Performance of Darrieus Vertical Axis Wind Turbine
}

\author{
${ }^{1}$ Taher G. Abu-El-Yazied, ${ }^{2}$ Hossam N. Doghiem*, ${ }^{3}$ Ahmad M. Ali, and \\ ${ }^{4}$ Islam M. Hassan \\ 1,2,3,4 Department of Design and Production Engineering, Faculty of Engineering, Ain Shams University, Cairo,
} Egypt.

\begin{abstract}
Vertical axis wind turbines (VAWTs) were originally considered as very promising for various reasons. There is now a resurgence of interests for VAWTs, in particular Darrieus turbines. Using modern design tools and computational approaches, it is possible to increase considerably the performance of traditional VAWTs, reaching a level almost comparable to that of horizontal axis turbines. Since VAWTs show many specific advantages (compact design, easier connection to gears/generator, easier blade control if needed, lower fatigue.), it is important to check quantitatively the efficiency of such turbines. In the present study, a barrier has been designed to increase the performance of the Darrieus wind rotor. The effect of this barrier on the rotor performance has been analyzed numerically; the barrier has been placed in front of the rotor. Numerical analysis has been carried-out for Darrieus wind rotor (with and without barrier). The power performance values of the rotor have been calculated by numerical analysis, and finally they have been compared. The obtained results show that higher performance when using the rotor with barrier. Finite Element analysis (FE) has been used as the Computational fluid dynamics (CFD) software.
\end{abstract}

Keywords: - Aerodynamic, Barrier, Computational fluid dynamics, Darrieus turbine.

\section{INTRODUCTION}

It is a well-known that wind energy is very important as one of clean energy resources, and wind rotors are the most important of the wind energy. There are two different physical principles to extract power from wind. The first of them is the airfoil drag method, and the second is the airfoil lift principle. The Darrieus turbine is the most common VAWT invented in 1931 [1-7] on the basis of the second principle. A lot of investigations aims to improve the performance of vertical axis wind turbine like Darrieus and Savonius by increasing wind velocity. [5, 11-12]

The present work aims to study the effect of barrier on the performance of the Darrieus vertical axis wind turbine through CFD simulations. In the present study, a barrier arrangement has been designed to deflect the wind for the purpose of increasing the low performance of the Darrieus wind rotor. This arrangement is both simple and cheap as it is composed of flat metal sheets. The effect of this barrier arrangement on the power performances values has been analyzed numerically.

\section{PROBLEM FORMULATION}

The speed ratio $(\lambda)$ is defined as:

$\lambda=\omega R / U$

A relation between the azimuth angle $\theta$, the angle of attack and the speed ratio $\lambda$ has been obtained from the velocity triangle in Fig., this relation is as follow:

$\alpha=\tan ^{-1}\left[\frac{\sin \theta}{\lambda+\cos \theta}\right]$

If the airfoil is set at an angle of incidence $\alpha$ in a fluid flow and according to the standard airfoil theory, it will generate a lift force $F_{L}$ normal to the free stream and a drag force $F_{D}$ in the direction of the free stream. These lift and drag forces can then be resolved to get the tangential force $F_{T}$ and the axial force $F_{N}$ as shown in Fig.. The tangential force $\mathrm{F}_{\mathrm{T}}$ has the instantaneous responsibility of the torque and the power outputs from the Darrieus turbine.

For a Darrieus rotor of height $\mathrm{H}$, a wind of incoming velocity $\mathrm{U}$, the mechanical power $\mathrm{P}$ and the mechanical torque on the axis of a Darrieus turbine can respectively be written as follows: 
$C_{m}=\frac{T}{\frac{1}{2} \rho A R U^{2}}$

$C_{p}=\frac{P}{\frac{1}{2} \rho A U^{3}}$

Where $\mathrm{C}_{\mathrm{m}}$ and $\mathrm{Cp}$ are respectively the torque coefficient and the power coefficient, $\mathrm{P}$ is the mechanical power extracted, $\rho$ is the air density, $\mathrm{A}$ is the turbine swept area, $\mathrm{R}$ is radius of turbine and $\mathrm{U}$ is wind free stream velocity. Power Coefficient depends on wind speed due to aerodynamic complexities of blade designs. [5]

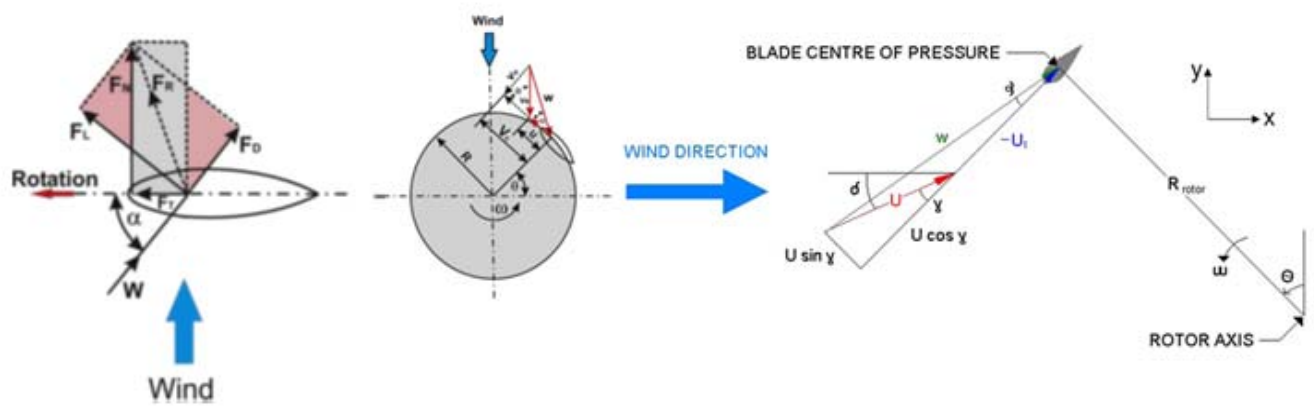

Fig. Forces and velocities distribution on Darrieus rotor airfoil [5, 8, 9]

\section{GEOMETRICAL MODEL}

The aim of the present work was to numerically analyze the aerodynamic behavior of a three-bladed Darrieus VAWT operating at different angular velocities for a constant wind speed of $9 \mathrm{~m} / \mathrm{s}$. The main geometrical features of the tested rotor are summarized in Table.. The solidity parameter $\sigma$ is defined as $\mathrm{Nc} / 2 * \mathrm{R}_{\text {rotor }}$, as suggested by Strickland [8-9]. Rotor azimuthal position was identified by the angular coordinate of the pressure center of blade No. 1 midsection (set at $0.25^{*} \mathrm{C}$ for NACA 0021 airfoil), starting between the 2 nd and 3rd Cartesian plane octants, as can be seen in Fig..

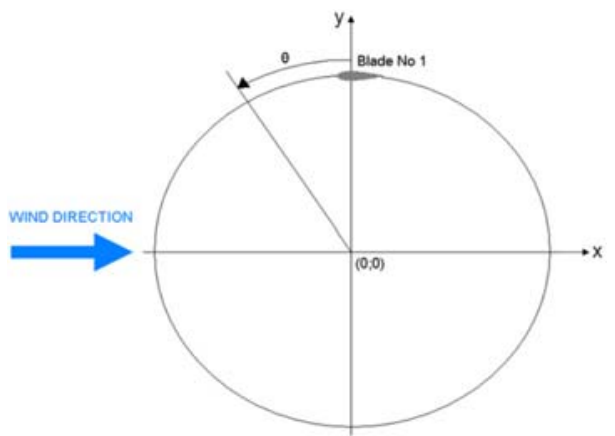

Fig. Azimuthal coordinate of blade midsection's center of pressure.

The main features of the validation model are summarized in Table.. [14]

Table. Validation model main features. [8-9]

\begin{tabular}{|c|c|}
\hline Drotor $[\mathrm{mm}]$ & 1030 \\
\hline Hrotor $[\mathrm{mm}]$ & 1414 \\
\hline $\mathbf{n}[-]$ & 3 \\
\hline Blade profile & NACA 0021 \\
\hline$A_{s}[\mathbf{m} 2]$ & 1.236 \\
\hline $\mathrm{H}_{\text {wind tunnel }}[\mathrm{mm}]$ & 4000 \\
\hline $\mathbf{W}$ wind tunnel [mm] & 3800 \\
\hline $\mathrm{C}[\mathrm{mm}]$ chord length & 85.8 \\
\hline Spoke-blade connection & $0.25 \mathrm{c}$ \\
\hline$\sigma[-]$ & 0.25 \\
\hline
\end{tabular}




\section{COMPUTATIONAL FLUID DYNAMICS (CFD) SIMULATION}

In the present study, Ansys Fluent 14.5 trade software has been used as one of the computational fluid dynamics (CFD) package programs. By using it, the Darrieus wind rotor with and without barrier in the static position has been analyzed from aerodynamic aspects. To do the numerical analysis in a shorter time, the model has been formed to have two dimensions.

The unsteady flow is solved by using the Sliding Mesh Model (SMM). Ten complete revolutions are often computed, using a calculated time-step for each tip speed ratio; the first revolutions is used to initiate the correct flow solution, while the flow properties (in particular the power coefficient $\mathrm{C}_{\mathrm{p}}$ and the torque coefficient $\mathrm{C}_{\mathrm{m}}$ ) are obtained by averaging the results during the last two revolutions. On a standard PC, one evaluation (i.e., ten revolutions for one specific configuration) takes about $500 \mathrm{~min}$ of computing time.

\section{Governing Equations}

The fluid dynamics equations have their mathematical representations which can be employed individually or in a group depending on the need of the desired output. Three basic principles which govern the characteristics of the flow of any fluid are conservation of mass, momentum and energy. In present case, we are dealing with the equation of continuity with the application of K- $\varepsilon$ model. The Continuity Equation or Conservation of Mass given by White (2005), for more general cases, the density " $\rho$ "can vary in time " $t$ " and in space" $\mathrm{x}, \mathrm{y}, \mathrm{z}$ and velocity " $\mathrm{u}$ " components in each of the three coordinate directions , and the continuity equation takes on the more familiar form as follows :

$\frac{\partial \rho}{\partial t}+\frac{\partial \rho u}{\partial x}+\frac{\partial \rho u}{\partial y}+\frac{\partial \rho u}{\partial z}=0$

Navier-Stokes Equation for an incompressible flow given by White (2005), as follows:

$\rho\left[\frac{\partial u_{i}}{\partial t}+u_{k} \frac{\partial u_{i}}{\partial x_{k}}\right]=-\frac{\partial P}{\partial x_{i}}+f_{i}+\mu \frac{\partial^{2} u_{i}}{\partial x_{k} \partial x_{k}}$

In Eq. (6), the convection terms are on the left. The terms on the right hand side are the pressure gradient, a source term; the divergence of the stress tensor, which is responsible for the diffusion of momentum; the gravitational force, another source term; and other generalized forces (source terms), respectively .Here f represents "other" body forces (per unit volume), such as gravity or centrifugal force and $\boldsymbol{\mu}$ represents viscosity. $[10,13]$

\section{Wind Tunnel as Open Domain Sub-Grid}

As the aim of the present work is the simulation of a turbine operating in open field conditions and because of the huge domain width necessary to avoid solid blockage, a domain size independence test is performed for one geometrical configuration. Several different two-dimensional by using Gambit 2.4, to find inlet and outlet boundary dimensions were respect to rotor radius.

Two symmetry boundary conditions were used for the two side walls. The circumference around the circular opening, centered on the turbine rotational axis, was set as an interface, thus ensuring the continuity in the flow field. A mesh was generated for the Wind Tunnel sub-grid, in order to reduce engineering time to prepare the CFD simulations. Fig3 shows the main dimensions and the boundary conditions of the Wind Tunnel sub-grid area.

\section{Domain Independent Test by Gambit 2.4}

The appropriate size of the computational domain has been investigated. A computational domain of increasing dimensions (square domain of size, suitably normalized by the rotor radius $\mathrm{R}$, in this work, the ratio between the square domain length and the rotor radius is 28 , after different domain sizes ranging from $20 \mathrm{R}$ to 60Rperformed for one geometrical configuration "at TSR 2.62" as a domain size independent test lead to a relative variation of the output quantity below $0.5 \%$, by using Gambit 2.4 for modeling and meshing and Ansys Fluent 14.5 for CFD simulation. 


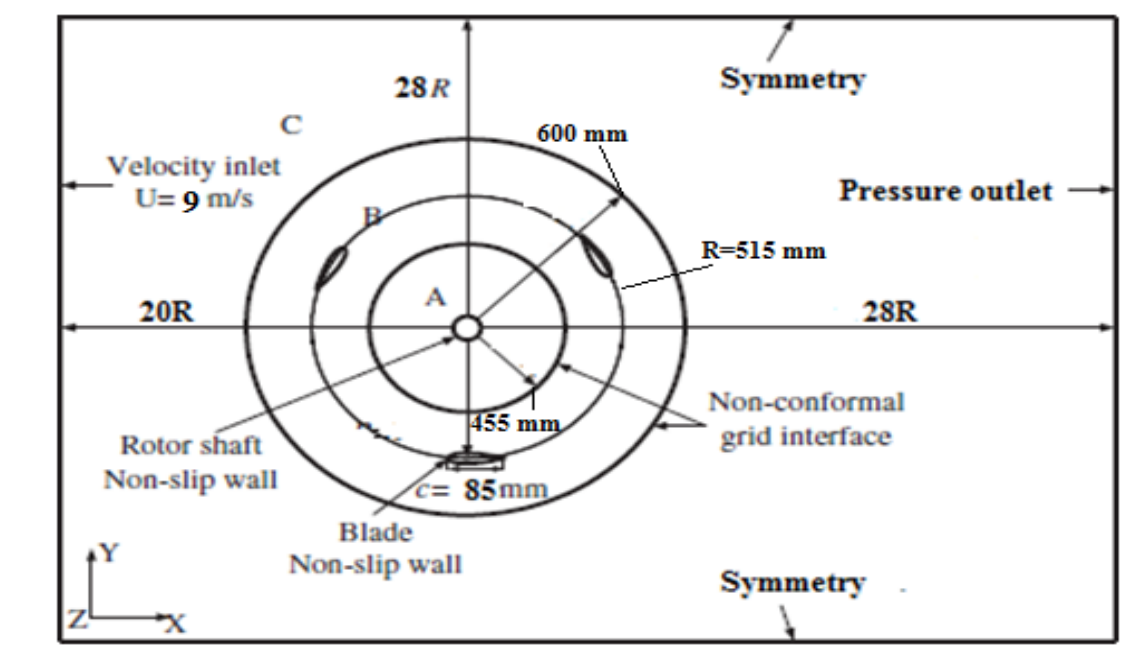

Fig.3Final scheme of geometry and boundary conditions for VAWT flow field simulation.

\section{Mesh Independent Test by Gambit 2.4}

Several different two-dimensional, unstructured grids of increasing density and quality, composed of different mesh size ranging from 130,000 up to 550,400 cells are investigated. This test shows that more than 149,125 cells lead to a relative variation of the output quantity below $1.3 \%$. After the appropriate size of the computational domain has been investigated, mesh size equal to 149,125 cells used for our present validation case.

\section{Turbulence Model Validation}

The effect of the turbulence model is validated and shown in Fig5. These results give a good agreement obtained between experiments and present CFD for the target function, Cp, when using the realizable k- $\varepsilon$ turbulence model. Same tendency has been observed for other studies, proving the interest of this model for fast CFD simulations. This model is usually recommended for rotating bodies. The realizable k- $\varepsilon$ model usually provides improved results for swirling flows and flows involving separation when compared to the standard k- $\varepsilon$ model. The near-wall treatment relies on standard wall functions. The $y+$ values found near all walls are around 40 and fall therefore within the recommended range for best-practice CFD $(30<y+<300)$. [10-13]

The two transport equations that need to be solved for this model are for the kinetic energy of turbulence, $\mathrm{k}$, and the rate of dissipation of turbulence, $\varepsilon$ :

$\frac{\partial(\rho k)}{\partial t}+\frac{\partial}{\partial x_{t}}\left(\rho u_{t} k\right)=\frac{\partial}{\partial x_{t}}\left(\mu+\frac{\mu_{t}}{\sigma_{k}}\right) \frac{\partial k}{\partial x_{t}}+G_{k}-\rho \varepsilon$

$\frac{\partial(\rho \varepsilon)}{\partial t}+\frac{\partial}{\partial x_{t}}\left(\rho u_{t} \varepsilon\right)=\frac{\partial}{\partial x_{t}}\left(\mu+\frac{\mu_{t}}{\sigma_{\varepsilon}}\right) \frac{\partial \varepsilon}{\partial x_{t}}+C_{1} \frac{\varepsilon}{k} G_{k}-C_{2} \rho \frac{\varepsilon^{2}}{k}$

The quantities $\mathrm{C} 1, \mathrm{C} 2, \sigma_{\mathrm{k}}$, and se are empirical constants. The quantity Gk appearing in both equations is a generation term for turbulence. It contains products of velocity gradients, and also depends on the turbulent viscosity:

$G_{k}=\mu_{t}\left(\frac{\partial u_{t}}{\partial x_{j}}+\frac{\partial u_{j}}{\partial x_{t}}\right) \frac{\partial u_{j}}{\partial x_{t}}$

Other source terms can be added to Equations (8) and (9) to include other physical effects such as swirl, buoyancy or compressibility, for example. The turbulent viscosity is derived from both $\mathrm{k}$ and $\varepsilon$, and involves a constant taken from experimental data, $\mathrm{Cm}$, which has a value of 0.09 :

$\mu_{t}=\rho C_{\mu} \frac{k^{2}}{\varepsilon}$

\section{Boundary Conditions}

There are various boundary types available in FLUENT like pressure inlet, velocity inlet, mass flow inlet, pressure outlet, pressure far-field, outflow, stationary wall, moving wall and axis. In this study, periodic boundary condition is applied to set the airfoils rotating. Boundary conditions used for the present case have been shown in Fig3. 
For this study a boundary pair of velocity inlet and pressure outlet is used. Pressure outlet boundary condition is generally suitable for the simulation of airfoil related problems. Airfoils are considered to be a no slip wall in reference to a moving fluid zone. The front of the domain was defined with boundary condition Velocity Inlet, which allowed the magnitude of inlet flow and turbulent quantities to be specified. The turbulent intensity of $0.1 \%$ and length scale of $0.005 \mathrm{~m}$ were applied to approximately account for the incoming flow turbulence in the wind tunnel. The published measurements were carried out at the "Politecnico di Milano" in Milan - Bovisa low turbulence wind tunnel. [8]

\section{Problem Setup In Fluent}

The present study involves the application of SIMPLE scheme. Among several special discretization schemes available in FLUENT, Least squares cell based gradient with Standard pressure and second order upwind scheme are found to be appropriate for the present study. Simulation begins with continues with the second order, and among several Transient formulation available second order implicit are found to be appropriate for the present work. Convergence criterion for the solution are set as 10-5. Currently, our area of consideration is to determine the forces acting on each of the three rotating airfoils and to obtain an optimum value of tip speed ratio which gives the maximum power output when wind passes the turbine at a speed of 9 $\mathrm{m} / \mathrm{s}$. In the present study Reynolds number is set as $0.553 \mathrm{e} 06$ for a rotor diameter of $1.03 \mathrm{~m}$. In the present case Reynolds number based on rotor diameter $\left(\operatorname{Re}_{\mathrm{D}}\right)$ is given by $[10,13]$ :

$R e_{D}=\frac{\rho V D}{\mu}=\frac{1.184 \times 9 \times 1.03}{1.983 \times 10^{-5}}=0.553 * 10^{5}$

Unsteady simulation involves time dependent calculations. Time step is calculated using speed of the rotor. Maximum iterations per time step set 100 iterations. The effect of rotor angle step on power coefficient at TSR 2.62 are investigated, this test shows that one degree step lead to a relative variation of the output quantity below $0.35 \%$. After the appropriate size of the computational domain has been investigated, so one degree found to be appropriate for the present validation study, but for small error less than $2.3 \%$ between two degree step and one degree step in value of power coefficient, two degree will be used to reduce computing time and cost for other simulations for the present work.

\section{Verification of the Simulation Results with Published Experimental Results}

Numerical turbulence model have been validated by comparison with published experimental results and CFD for an H-rotor Darrieus turbine [8-9]. The effect of the turbulence model is shown in Fig4. These results give a good agreement obtained between experiments and present CFD for the target function, $\mathrm{Cp}$, when using the realizable k- $\varepsilon$ turbulence model.

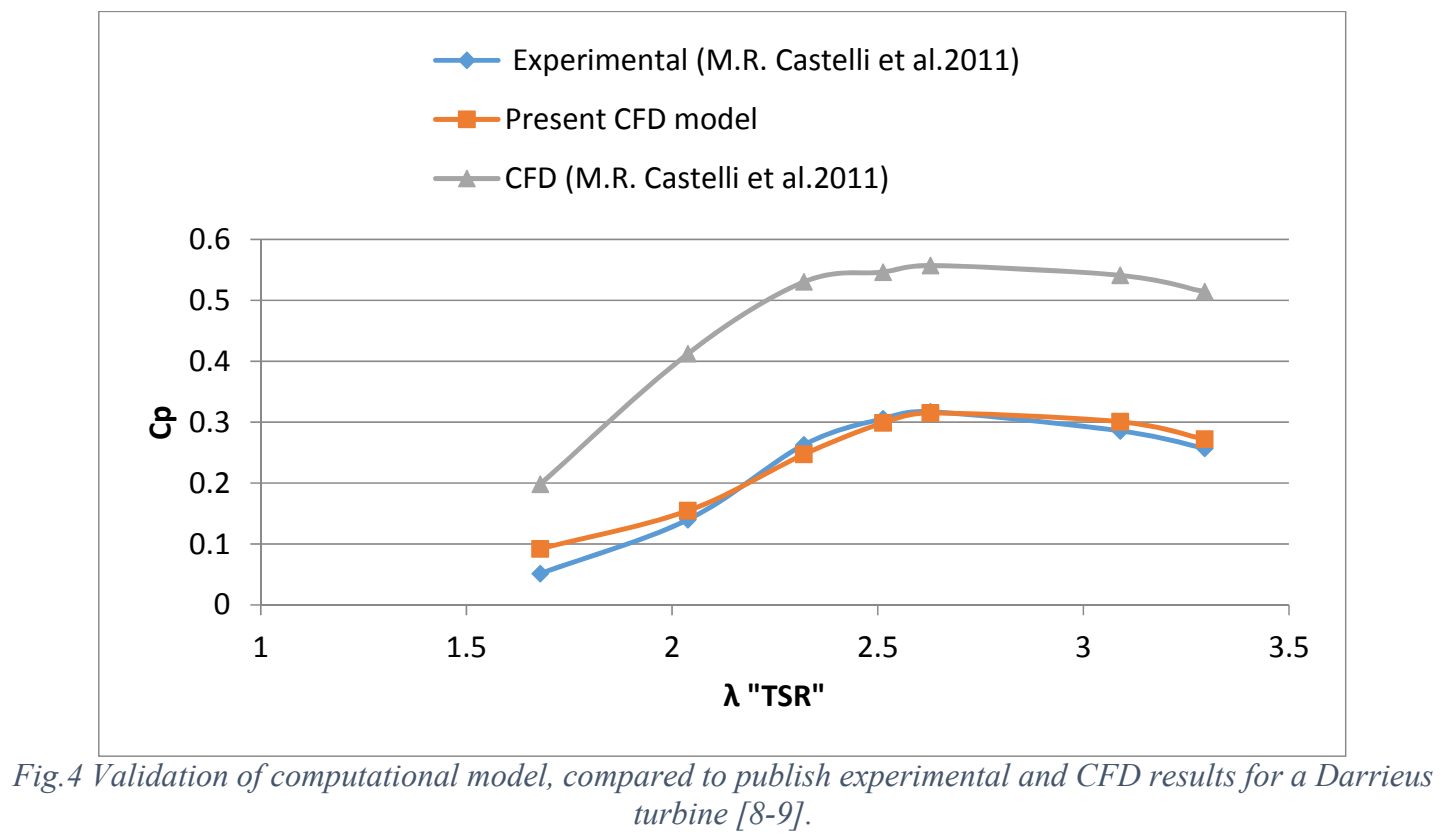


The optimal mesh configurations used in the CFD model of the single static airfoil were transferred into the VAWT model with new boundary adaption (shown in Fig5). The total number of grids in the 2D VAWT model was 149,125 cell.

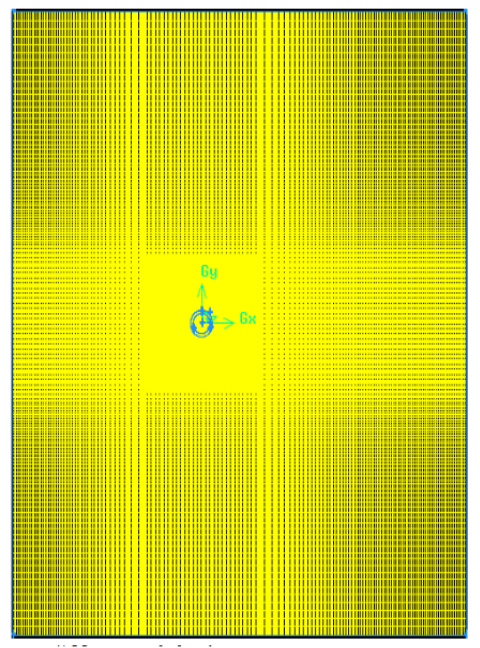

A) Mesh for whole domain

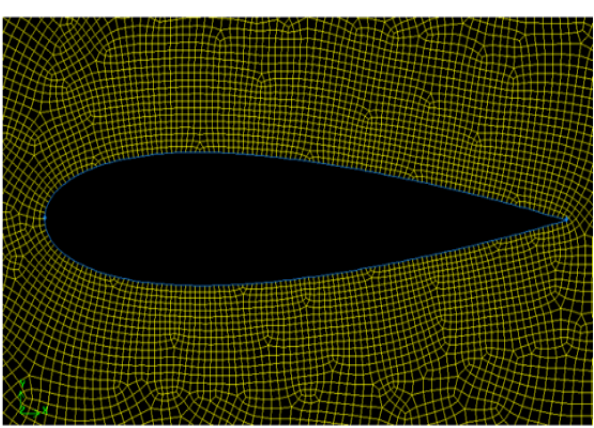

C) Mesh around blade

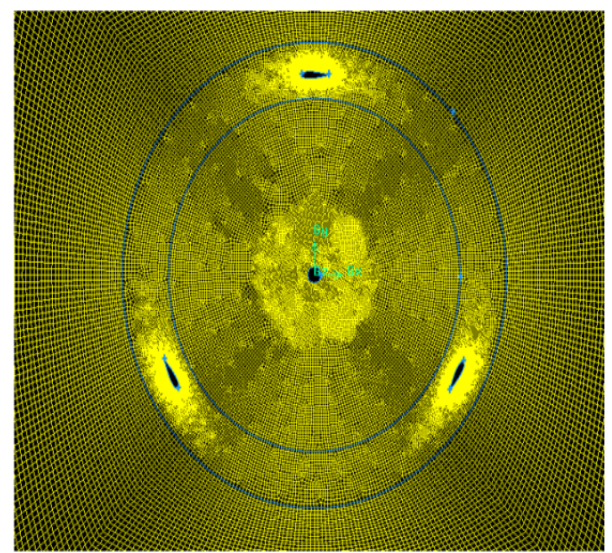

B) Mesh of rotational ring

domain

Fig.5 Mesh distribution for VAWT flow field simulation.

\section{DESIGN OF THE DARRIUS WIND ROTOR AND THE BARRIER ARRANGEMENT}

To increase the rotor performance, it is important to prevent the negative torque that forms in the adverse direction of the rotor's rotating direction. A new design has been put forward for the purpose of increasing the performance of the Darrieus wind rotor without making any modifications in its basic structure. To increase the performance coefficients and the effects of the wind speed, a barrier arrangement has been placed in front of the rotor as shown in Fig. 6 . So that it can prevent the negative torque that forms in the adverse direction of the rotor's rotating direction.

In this barrier arrangement, $\alpha-\beta$ represents the angles of curtain plates while ' 11 and ' 12 are the lengths of barrier plates. Dimensions of 6 different curtain arrangements simulated are given in Fig.7 Wind rotor cad model with and without barrier

Table.2. Barrier arrangements have been designed as shown in Fig7 in such a way as to rotate by $360^{\circ}$ around the rotor.

\section{MESH GENERATED AND BOUNDARY CONDITIONS FOR PRESENT MODEL}

Airfoils are considered to be a no slip wall in reference to a moving fluid zone. Barriers are considered to be a stationary wall in reference to a moving fluid zone. A mesh was generated for the Wind Tunnel sub-grid, in order to reduce engineering time to prepare the CFD simulations. In order to avoid negative pressure during simulation, the ratio between outlet length form rotor center and the rotor radius is 60 as shown in Fig8. 


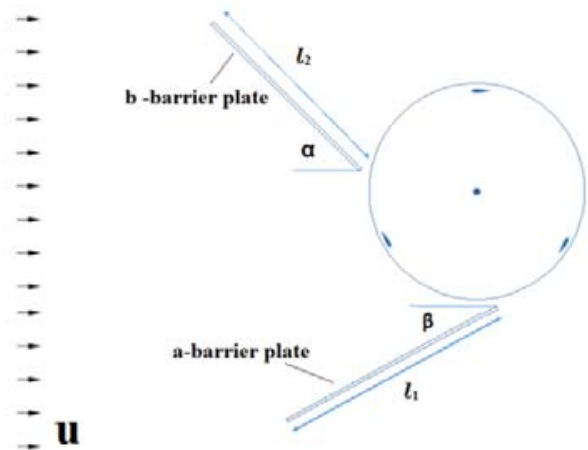

Fig. 6 Design of the barrier arrangement placed in front of the Darrieus wind rotor

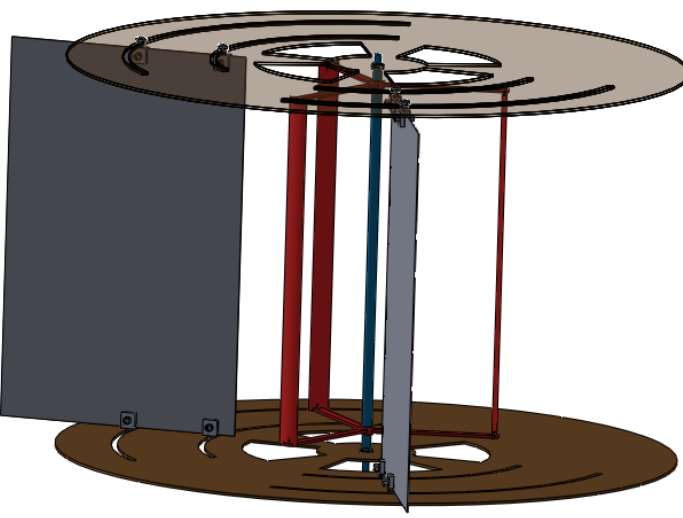

1-Wind rotor with barrier

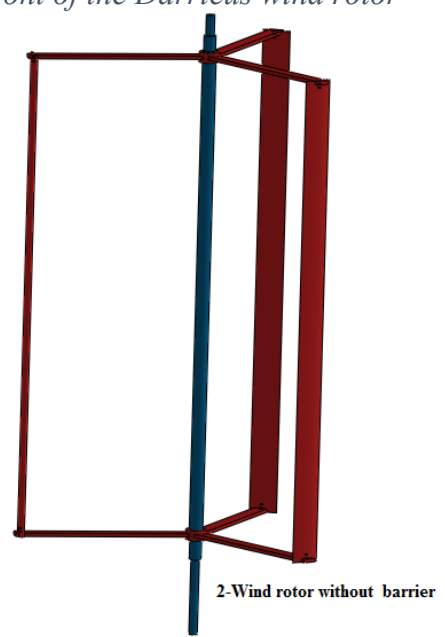

Fig.7 Wind rotor cad model with and without barrier

Table. 2 Dimensions of the barrier arrangement.

\begin{tabular}{|l|l|l|l|l|}
\hline $\begin{array}{l}\text { Types of Barrier } \\
\text { arrangement }\end{array}$ & $\begin{array}{l}\text { Distancel }_{1} \\
(\mathrm{~cm})\end{array}$ & $\begin{array}{l}\text { Distancel }_{2} \\
(\mathrm{~cm})\end{array}$ & $\begin{array}{l}\text { Height H } \\
(\mathrm{cm})\end{array}$ & $\begin{array}{l}\text { Thickness } \\
\mathrm{t} \\
(\mathrm{cm})\end{array}$ \\
\hline Barrier 1 & 200 & 250 & 145 & 4 \\
\hline Barrier 2 & 250 & 300 & 145 & 4 \\
\hline Barrier 3 & 100 & 150 & 145 & 4 \\
\hline Barrier 4 & 50 & 100 & 145 & 4 \\
\hline Barrier 5 & 50 & 50 & 145 & 4 \\
\hline Barrier 6 & 25 & 25 & 145 & 4 \\
\hline
\end{tabular}

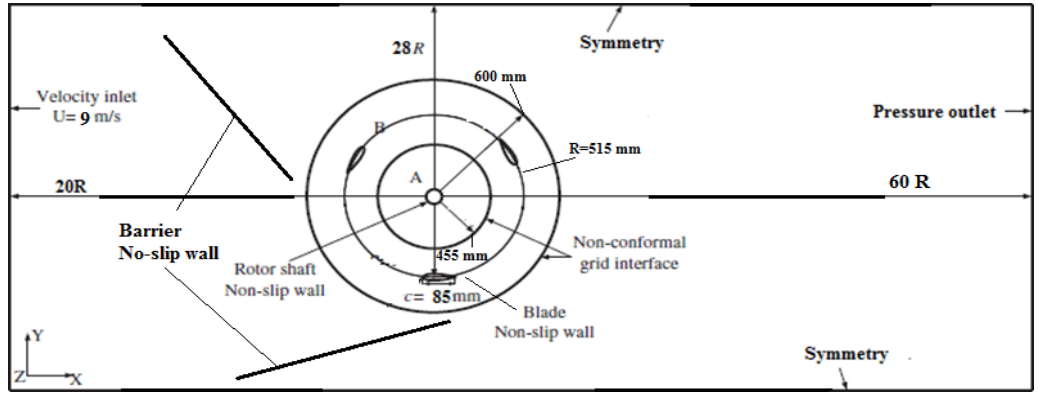

Fig. 8 Scheme of geometry and boundary conditions for VAWT flow field simulation with barrier in front of wind rotor. 
Fig9 shows the mesh configurations used in the CFD model of the single static airfoil were transferred into the VAWT model with new boundary adaption. The near-wall treatment relies on standard wall functions. In this study realizable $\mathrm{k}-\varepsilon$ turbulence model has been used in the analysis of turbulent flow. The $\mathrm{y}+\mathrm{values}$ found near all walls fall within the recommended range for best-practice CFD $(30<\mathrm{y}+<300)$. [10-13]

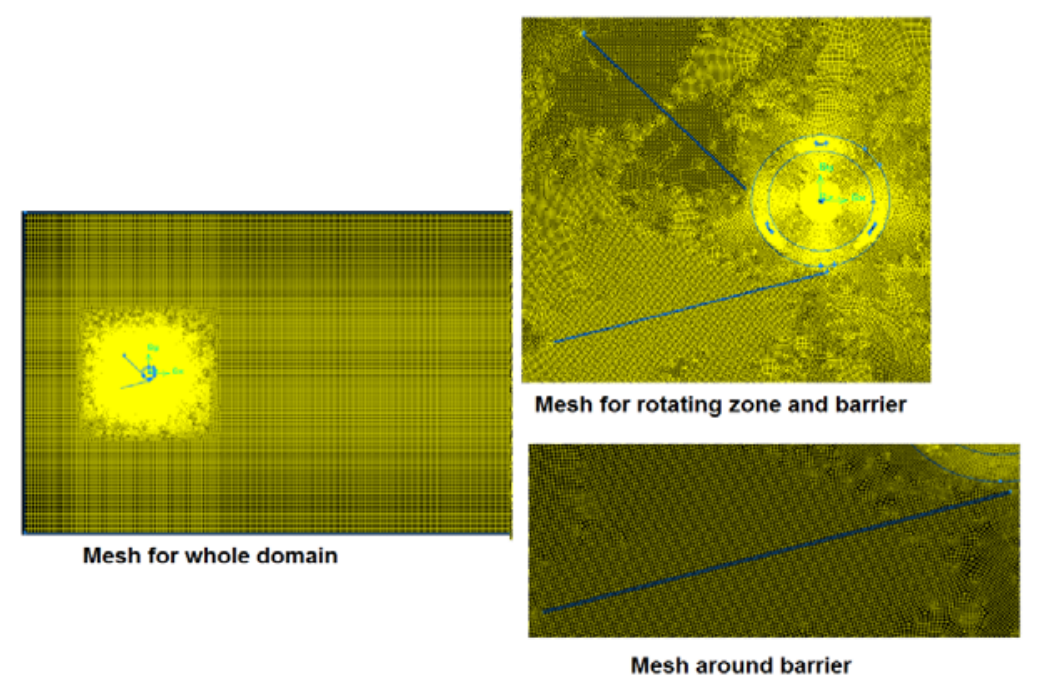

Fig.9 Mesh distribution for VAWT flow field simulation at barrier 1 with $\alpha=45^{\circ}$ and $\beta=15^{\circ}$

The unsteady flow is solved by using the Sliding Mesh Model (SMM). Ten complete revolutions are often computed, in case of rotor with barrier about 1500 iterations in steady flow is solved first to initialize solution to unsteady flow.

\section{RESULTS AND DISCUSSION}

The power coefficients "Cp"have been found with different tip- speed ratios $\lambda$ for the rotor with and without barrier through numerical analysis made by using Ansys Fluent 14.5 program after validated by comparison with published experimental results and CFD for an H-rotor Darrieus turbine as we discussed above. It is seen both from the published experimental and the numerical analysis that the power coefficients values at tip- speed ratio $\lambda 2.62$ (Fig4). The velocity and Pressure distributions obtained through numerical analysis for rotor without barrier are given in Fig. 10.
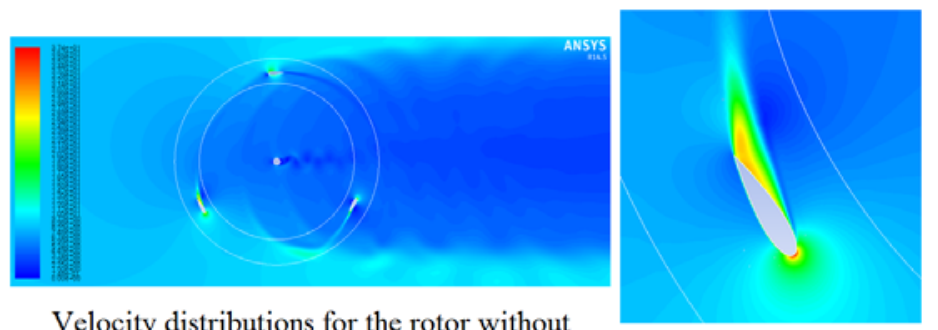

Velocity distributions for the rotor without barrier
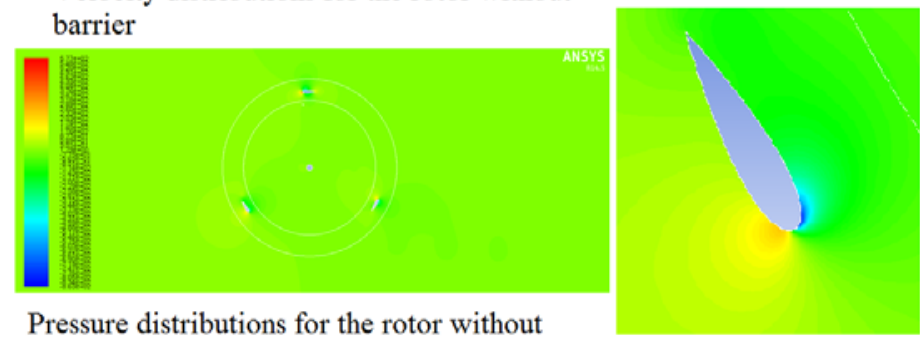

Pressure distributions for the rotor without barrier

Fig.10 Velocity and Pressure distributions for the rotor without barrier at TSR 2.62 on rotor and around blade. 
In the present study, to increase the performance of the Darrieus wind rotors, a barrier arrangement formed from wind deflecting plates has been placed in front of the rotor so as to prevent the negative torque. In doing so, the aim is to increase the speed of the wind entering the rotor and thus to improve its efficiency. To analyze the effects of barrier angles ( $\alpha$ and $\beta$ ), influential in the barrier design.

In the same way, numerical analysis have been made for different barrier angles ( $\alpha$ and $\beta$ ). This numerical analysis is made through Barrier1 (

Table.2). shows the a angle-related changes of the power performance " $\mathrm{Cp}$ " values obtained for the Barrier1 through numerical analysis made at the values of different tip-speed ration " $\lambda$ ". It is seen here that the power performance values obtained for Barrier1 at $\beta=80^{\circ}$ and $\alpha=80^{\circ}$ through numerical analysis are the highest power performance value has been found. This analysis is shown in Fig11 and Fig12.The velocity and Pressure distributions obtained through numerical analysis for rotor with barrier1 at $\alpha$ and $\beta$ equal to $80^{\circ}$ are given in Fig13.

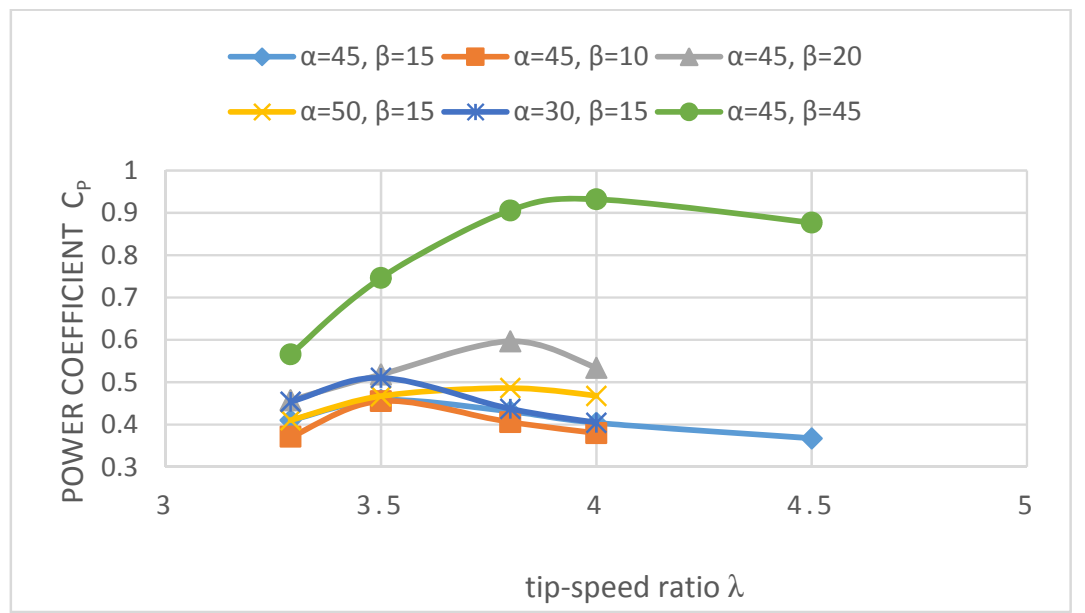

Fig.11Effect of both angles $\alpha$ and $\beta$ on Power Coefficient Cp at different tip speed rations $\lambda$. (Angles $\alpha$ and $\beta$ will be taken lower than $45^{\circ}$ )

Then numerical analysis is made through Barrier1, Barrier2, Barrier3, Barrier4, Barrier5 and Barrier6 (

Table.2). The angles $\beta=80^{\circ}$ and $\alpha=80^{\circ}$ are used for all barriers dimension's .This analysis is shown in Fig14.From this analysis as dimensions of barrier is higher as power performance values are higher.

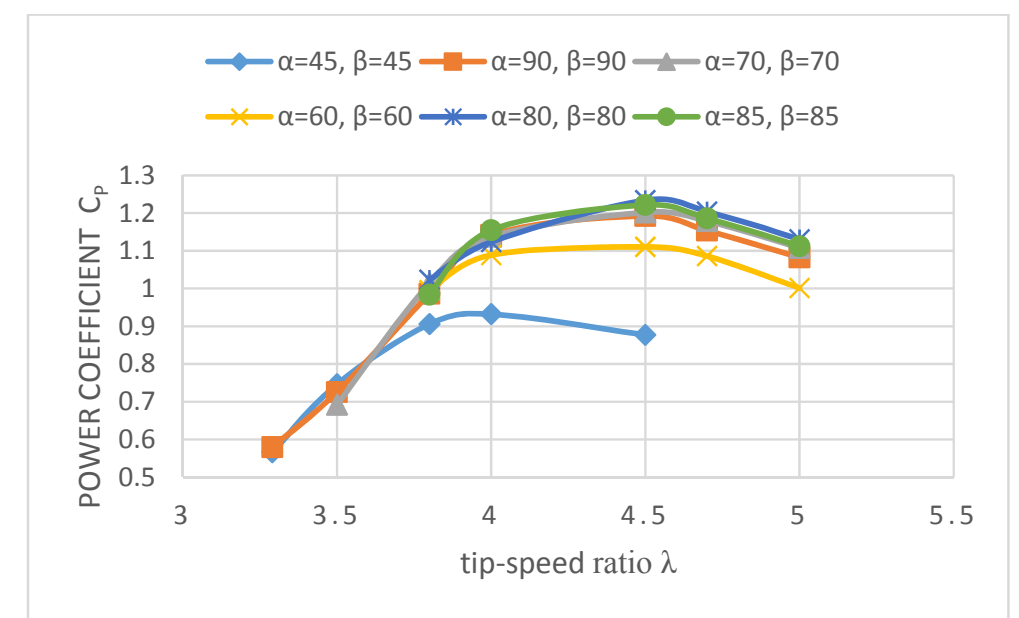

Fig. 12 Effect of both angles $\alpha$ and $\beta$ on Power Coefficient Cp at different tip speed rations $\lambda$. (Angles $\alpha$ and $\beta$ will be taken upper than $45^{\circ}$ ) 
Finally numerical analysis is made through different positions of Barrier1 as shown in Fig15. The angles $\beta=80^{\circ}$ and $\alpha=80^{\circ}$ are used for all barriers dimension's .This analysis is shown in Fig16. From this analysis position A will be the more effective position on power performance value.

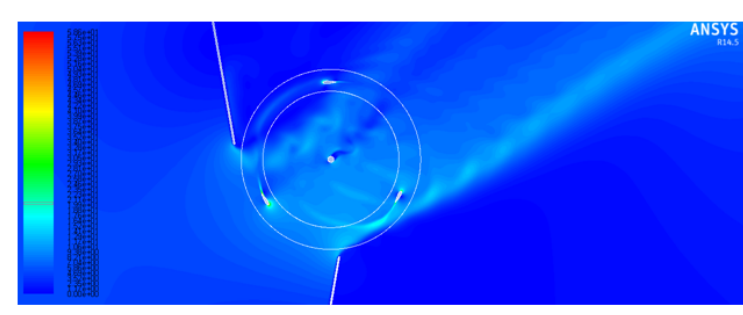

Velocity distributions for the rotor with barrier at TSR 4.5
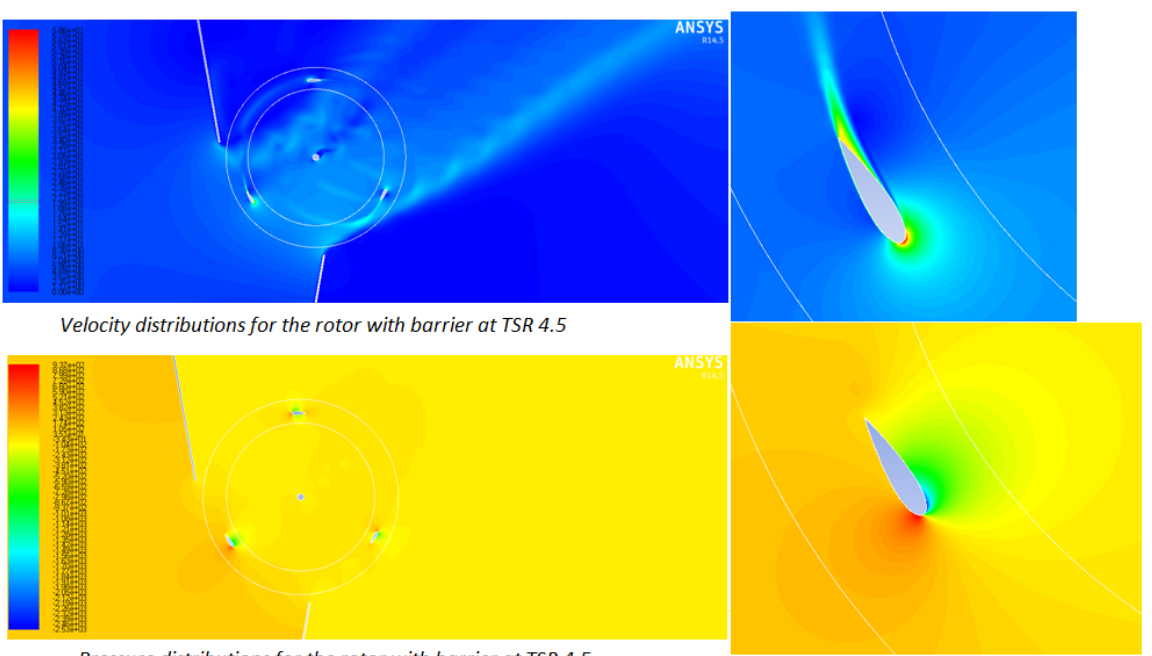

Pressure distributions for the rotor with barrier at TSR 4.5

Fig13 Velocity and Pressure distributions for the rotor with barrier at TSR 4.5 on rotor and around blade.

VIII.

CONCLUSION AND FUTURE WORK

A barrier arrangement, which is a simple wind deflector, has been designed and placed in front of the rotor to prevent the negative torque and also to increase the velocity of the wind entering the rotor for the purpose of increasing the performance of the Darrieus wind rotor in the present study. A comparison between the results obtained through published experiments and numerical analysis has shown that the rotor with barrier can provide a better performance than the rotor without barrier. In the rotor with barrier, the best torque values have been obtained with the Barrier 2, which is the longest one. On the other hand, it has been indicated by numerical analysis that the best performance for wind rotor is obtained at $\alpha=80^{\circ}$ and $\beta=80^{\circ}$. In addition to this analysis, it has been indicated by numerical analysis that the best performance for wind rotor is obtained when barrier put before wind rotor in the side ends as in position A. The published experimental and numerical results are much close to each other in case of wind rotor without barrier has indicated that the choices of model, method and algorithm used in the numerical analysis are proper for the study.

For future work, mechanical analysis will be made through wind rotor after put barrier in front of wind rotor and study stress distribution and vibration on blade after increase pressure on blade and optimize the thickness of blade using Ansys workbench 14.5.

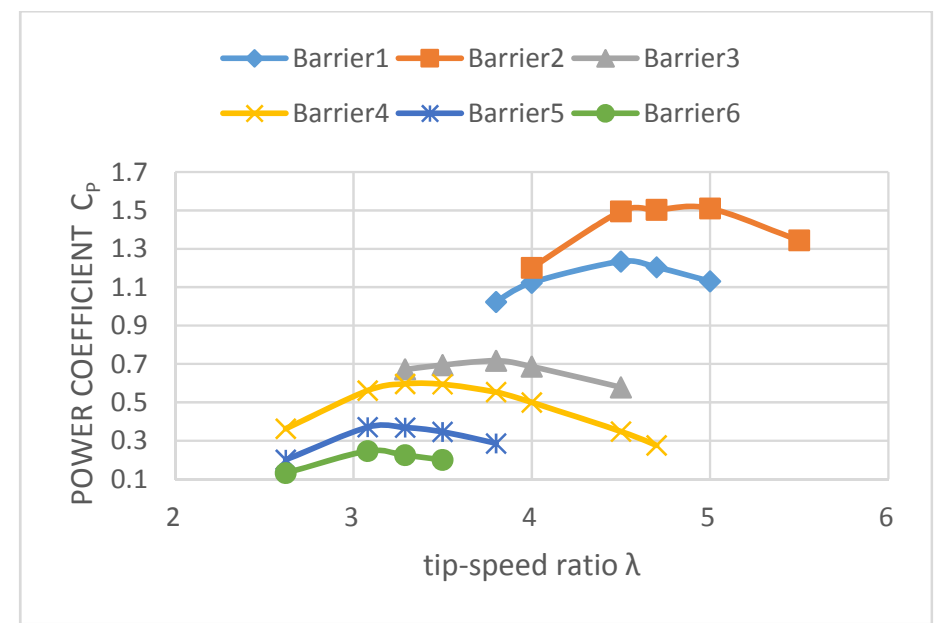

Fig.14 Effect of both barrier dimensions on Power Coefficient Cp at different tip speed rations $\lambda$. (Angles $\alpha$ and $\beta$ will be taken $80^{\circ}$ ) 


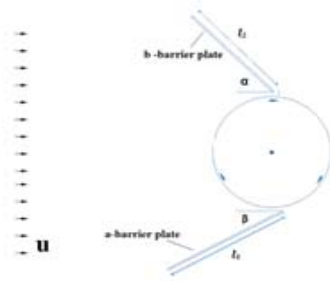

A

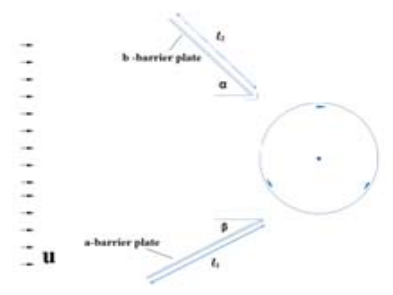

B

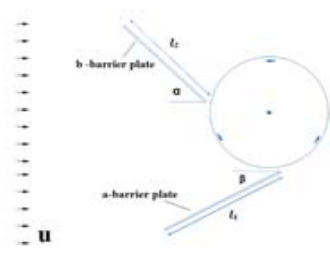

C

Fig. 15 Different Positions of Barrier1 relative to wind rotor (Angles $\alpha$ and $\beta$ will be taken $80^{\circ}$ )

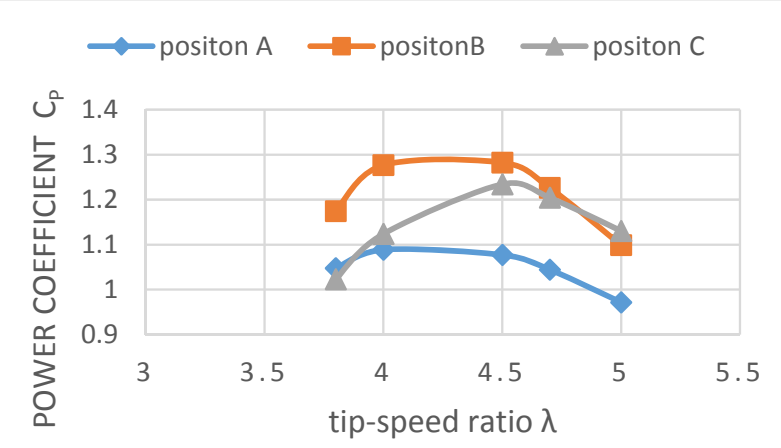

Fig.16Effect of barrier position on Power Coefficient Cp at different tip speed rations $\lambda$. (Angles $\alpha$ and $\beta$ will be taken $\left.80^{\circ}\right)$

\section{REFERENCES}

[1] T. Price, UK large-scale wind power programme from 1970 to 1990: the Carmarthen Bay experiments and the Musgrove vertical-axis turbines, Wind Engineering, 30(3): 225-42, 2006.

[2] J. German, The end of an era: Sandia's 17-meter vertical axis wind turbine comes down after two decades, Sandia Lab News, LN11-21-97, 1997.

[3] P. Musgrove, Wind energy conversion: Recent progress and future prospects, Solar and wind technology, 4(1): 37- 49, 1987.

[4] D. Berg, P. Klimas, W. Stephenson, Aerodynamic design and initial performance measurements for the Sandia 34- $m$ vertical axis wind turbine, In: Proceedings of the ninth ASME wind energy symposium, Sandia National Laboratories, SED-VOL 9, ASME, 1990.

[5] Mohamed MH. Design optimization of Savonius and wells turbine. Ph.D. Thesis, LSS-S01/11, Univ. of Magdeburg, Germany, 2011.

[6] Kaltschmitt M, Streicher W, Wiese A. Renewable energy, technology and environment economics. Berlin, Heidelberg: Springer-Verlag; 2007.

[7] Mukinovic M, Brenner G, Rahimi A. Analysis of vertical axis wind turbines. In: Dillmann A, et al., editors. Numerical and experimental fluid mechanics, vol. 112. Berlin, Heidelberg: Springer-Verlag; 2010.

[8] Raciti Castelli M, Pavesi G, Battisti L, Benini E, Ardizzon G. Modeling strategy and numerical validation for a Darrieus vertical axis micro-wind turbine. Vancouver, British Columbia, Canada: ASME 2010 International Mechanical Engineering Congress \& Exposition; November 12e18, 2010. IMECE201039548.

[9] Castelli MR, Englaro A, Benini E. The Darrieus wind turbine: proposal for a new performance prediction model based on CFD. Energy 2011; 36(6):4919e34.

[10] Malalasekera, H. K. (Second edition published 2007). An Introduction to Computational Fluid Dynamic. Bell \& Bain Limited, Glasgow.

[11] Altan, B. D. (2008). An experimental and numerical study on the improvement of the performance of. Energy Conversion and Management: 3425-3432,2008.

[12] Chong, W. The design, simulation and testing of an urban vertical axis wind turbine. Applied Energy: 601-609,2013.

[13] Fluent Inc., Fluent User’s Manual. 2006. pp. 52, 54, 59, 71, 143. 
A: projected area of rotor $(\mathrm{DH}), \mathrm{m} 2$

Cp: power coefficient (P/ [1/2rAU3])

$\mathrm{Cm}$ : torque coefficient (T/ [rR2HU2])

C: blade chord, $\mathrm{m}$

D: turbine diameter (2R), $m$

$\mathrm{F}_{\mathrm{L}}$ : lift force, $\mathrm{N}$

$\mathrm{F}_{\mathrm{D}}$ : drag force, $\mathrm{N}$

$\mathrm{F}_{\mathrm{T}}$ : tangential force, $\mathrm{N}$

$\mathrm{F}_{\mathrm{N}}$ : axial force, $\mathrm{N}$

$\mathrm{F}_{\mathrm{R}}$ : resultant force, $\mathrm{N}$

$\mathrm{H}$ : blade height, $\mathrm{m}$

$\mathrm{N}$ : rotational speed of rotor, rpm

n: number of blades

$\mathrm{P}$ : output power $(2 \pi \mathrm{NT} / 60), \mathrm{W}$

$\mathrm{R}$ : radius of turbine, $\mathrm{m}$

$\mathrm{T}$ : output torque, $\mathrm{Nm}$

$\mathrm{U}$ : mean wind velocity in axial direction, $\mathrm{m} / \mathrm{s}$

$\mathrm{u}$ : peripheral velocity of the blade, $\mathrm{m} / \mathrm{s}$

$\alpha$ : angle of attack, $\left({ }^{\circ}\right)$

$\sigma$ : solidity, (nc/2R)

$\lambda$ : TSR tip-speed ratio, $(\mathrm{uR} / \mathrm{U})$

$\rho$ : density, $\mathrm{kg} / \mathrm{m} 3$

$\theta$ : azimuth angle, $\left({ }^{\circ}\right)$

$\mathrm{U}_{\mathrm{t}}:[\mathrm{m} / \mathrm{s}]$ blade tangential speed at blade position
Apendix

$\omega$ : angular speed, $1 / \mathrm{s}$

$\mathrm{S}_{\text {domain: }}:[\mathrm{mm} 2]$ computational domain section

$\mathrm{W}_{\text {domain: }}[\mathrm{mm}]$ computational domain width

$\mathrm{W}_{\text {wind tunnel: }}[\mathrm{mm}]$ computational domain width, validation model

$\mathrm{H}_{\text {domain: }}[\mathrm{mm}]$ computational domain height

$\mathrm{H}_{\text {rotor: }}:[\mathrm{mm}]$ rotor height

$\mathrm{H}_{\text {windtunnel: }}[\mathrm{mm}]$ computational domain height,

validation model

$\mu$ : Viscosity ( $\mathrm{kg} / \mathrm{m} \mathrm{s})$

$\mathrm{V}_{\text {test section: }}[\mathrm{m} / \mathrm{s}]$ mean wind velocity at rotor test section $\mathrm{V} \infty:[\mathrm{m} / \mathrm{s}]$ unperturbed wind velocity at computational domain entrance

$\mathrm{w}:[\mathrm{m} / \mathrm{s}]$ relative wind velocity at blade position

$\mathrm{k}$ :kinetic energy of turbulence

$\varepsilon$ :the rate of dissipation of turbulence

$\mathrm{Re}_{\mathrm{D}}:[-]$ blade Reynolds numbers

$\mathrm{U}_{\mathrm{x}}:[\mathrm{m} / \mathrm{s}]$ absolute wind velocity at blade position, component along $\mathrm{x}$ axis

$\mathrm{U}_{\mathrm{y}}:[\mathrm{m} / \mathrm{s}]$ absolute wind velocity at blade position, component along y axis 